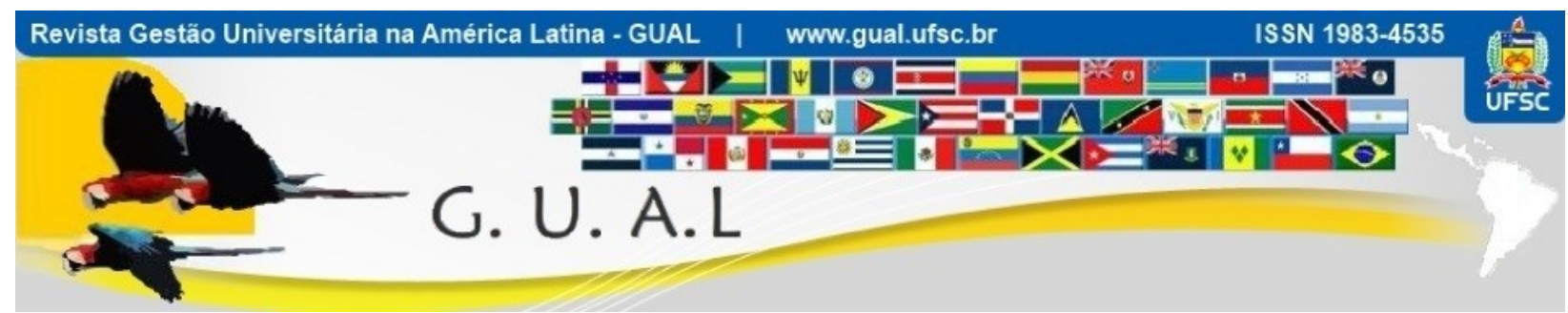

DOI: http://dx.doi.org/10.5007/1983-4535.2016v9n2p301

\title{
ANÁLISE DO INSTRUMENTO DE AVALIAÇÃO DE CURSOS EM UMA INSTITUIÇÃO DE ENSINO SUPERIOR DA SERRA GAÚCHA
}

\author{
ANALYSIS OF COURSE ASSESSMENT TOOL IN A HIGHER EDUCATION \\ INSTITUTION OF THE SERRA GAUCHA
}

Cesar Pandolfi, Doutorando Faculdade da Serra Gaúcha - FSG cesar.pandolfi@,fsg.br

Carla Schwengber ten Caten, Doutora Universidade Federal do Rio Grande do Sul - UFRGS tencaten@producao.ufrgs.br

Cláudia Medianeira Cruz Rodrigues, Doutora Universidade Federal do Rio Grande do Sul - UFRGS claudia.rodrigues@producao.ufrgs.br

Recebido em 04/novembro/2014

Aprovado em 20/janeiro/2016

Sistema de Avaliação: Double Blind Review

Esta obra está sob uma Licença Creative Commons Atribuição-Uso. 


\title{
RESUMO
}

Esta pesquisa objetivou avaliar as mudanças realizadas no instrumento de coleta de dados para avaliação institucional de cursos de uma Instituição de Ensino Superior da Serra Gaúcha. Utilizou-se a análise da consistência interna do instrumento e a análise multivariada dos resultados da avaliação dos cursos. Caracteriza-se como um estudo de caso, de natureza aplicada e descritiva. A coleta de dados ocorreu no segundo semestre de 2013 e obteve um retorno de 8.854 respondentes. Os resultados estão estruturados em dois fatores, bem como divididos pelos 16 cursos pesquisados. O estudo contribuiu para verificar que o instrumento se mostra adequado e evidenciou que as respostas podem ser agrupadas em três níveis de satisfação. Por fim, serve de base para análise e reorganização das práticas adotadas pelos cursos, tendo referência os aspectos identificados que servem como norteadores de ações de melhoria.

Palavras-chave: Avaliação. Instrumento. Instituição de educação superior.

\begin{abstract}
This research aimed to evaluate the changes made in the data collection instrument for institutional evaluation courses in a higher education institution of the Serra Gaucha. We used the analysis of the instrument's internal consistency and multivariate analysis of the evaluation results of the courses. It is characterized as a case study, applied and descriptive nature. Data collection occurred in the second half of 2013 and achieved a return of 8.854 respondents. The results are structured on two factors, and divided by the 16 surveyed courses. The study contributed to identifying the instrument shown adequate and showed that responses can be grouped into three levels of satisfaction. Finally, the basis for analysis and reorganization of the practices adopted by the courses, and reference the identified aspects that serve as a guide for improvement actions.
\end{abstract}

Key-words: Evaluation. Instrument. Higher education institution. 


\section{INTRODUÇÃO}

O setor de serviços cresce na medida em que a população aumenta a capacidade de consumo, o que pode ser observado na demanda por serviços educacionais, pois os profissionais necessitam estar com formação adequada às exigências do mercado. Observa-se que este início de século é marcado pela grande busca à educação, em especial pelo ensino superior que cresce como resultado da necessidade de qualificação profisssional (PALÁCIO et al., 2002; MEYER JR.; MURPHY; 2003; MICHAEL, 2004).

Segundo dados do censo de 2012, o número de Instituições no Brasil aumentou para 2365, destas: 284 Instituições são Públicas (103 federais; 110 estaduais e 71 municipais) e 2081 Instituições são Privadas. Para o Rio Grande do Sul esta realidade não é diferente sendo que são 111 Instituições onde são 10 Instituições Públicas e 101 Privadas. Destas 101 Instituições Privadas, 61 são do interior (INEP, 2012).

Essa área vem enfrentando o desafio da concorrência, que nos últimos anos está cada vez mais disputada. O aumento das matrículas nos sistemas de educação superior que ocorreu em vários países a partir da década de 1960 resultou, para alguns deles, na disseminação de instituições de ensino que atuam em condições inadequadas de infraestrutura e recursos humanos, e cujos projetos curriculares nem sempre atendem às demandas apresentadas pelo processo acelerado de produção e difusão do conhecimento (PEIXOTO, 2008).

O modo desordenado que se deu a expansão do sistema de educação superior no final do século XX chamou a atenção dos gestores e formuladores de políticas para a necessidade da aplicação de instrumentos de avaliação, destinados a assegurar níveis de qualidade capazes de corresponder às demandas de formação profissional e de atender a critérios científicos e acadêmicos reconhecidos internacionalmente (PEIXOTO, 2008).

$\mathrm{O}$ crescimento do setor de ensino passa necessariamente pela competitividade entre as Instituições de Ensino Superior (IES), que buscam formas de se diferenciar através do desenvolvimento de novos métodos de ensino e processos de serviços mais eficazes, com qualidade superior a custos suportáveis. Neste contexto competitivo a gestão da IES ganha importância significativa, pois processos monitorados contribuem para a atração de novos alunos e para a conservação dos já existentes. Assim, este estudo evidencia o seguinte problema de pesquisa como norteador do estudo: "O Instrumento de avaliação de cursos aplicado atualmente pela Instituição em estudo é consistente e existem diferenças entre cursos de graduação na avaliação do trabalho docente quando analisados sob os mesmos 
instrumentos de coleta de dados? "O estudo foi realizado em uma Instituição de Ensino Superior da Serra Gaúcha que será tratada durante o texto como Instituição A.

Com base neste problema, este artigo tem como objetivo principal analisar a consistência interna e os resultados do instrumento de avaliação dos cursos aplicados a uma IES. Para atender este objetivo foram elencados alguns objetivos específicos: (i) avaliar o instrumento aplicado quanto a sua efetividade (consistência interna); (ii) analisar o comportamento dos diferentes cursos; (iii) analisar a existência de correlação entre os itens do instrumento; (iv) validar os fatores através da análise fatorial; (v) analisar se existe diferenças significativas entre os cursos no que diz respeito ao trabalho docente e, (vi) avaliar através da análise de Cluster como está o comportamento das respostas. Para melhor estruturar e atender o objetivo, o estudo está dividido em cinco capítulos, sendo que o primeiro capítulo apresenta a introdução, a problemática e o objetivo proposto; o segundo capítulo apresenta o referencial teórico acerca de Avaliação Institucional e Análise Multivariada; o terceiro capítulo trata dos procedimentos metodológicos adotados para o levantamento dos dados; o quarto capítulo apresenta e discute os resultados; e o quinto capítulo apresenta as considerações finais do estudo.

\section{REFERENCIAL TEÓRICO}

\subsection{AVALIAÇÃO INSTITUCIONAL}

No Brasil, devido às divergências teóricas, ideológicas e políticas, além dos diferentes interesses pessoais, corporativos ou sociais, o sistema de educação superior apresenta características singulares e torna a prática da avaliação relativamente complexa. Isso se deve também ao desenvolvimento da avaliação depender de respostas sobre suas finalidades, de quem analisa os resultados e dos critérios sobre os quais a análise é fundamentada (GIANOTTI, 2004).

Segundo Ribeiro (2012), uma das primeiras ações legais acerca do que e de como deveria ser a avaliação da educação superior no governo de Fernando Henrique Cardoso (FHC) foi a promulgada Lei $\mathrm{n}^{\circ}$. 9.131/95, de criação do Exame Nacional de Curso (ENC), conhecido popularmente por Provão. Os resultados do Provão provocaram o estabelecimento de ranking interinstitucional, criando-se situações embaraçosas para as instituições e seus alunos, caso o desempenho não fosse favorável. Por sua vez, o governo LULA propõe em abril de 2004, a Lei ${ }^{\circ}$ 10.861, que criou o Sistema Nacional de Avaliação da Educação 
Superior (SINAES). O objetivo proposto para este novo modelo é o de avaliar os aspectos concernentes ao ensino, à pesquisa e à extensão, além disso, à responsabilidade social, ao desempenho dos alunos, e aspectos da gestão da instituição, do corpo docente e das instalações. A situação atual é a de que a avaliação da educação superior é regulada pelos dois novos índices criados: o Conceito Preliminar de Curso (CPC) e o Índice Geral de Cursos da Instituição de Educação Superior (IGC) (TAVARES; OLIVERA; SEIFFERT, 2011).

A lei $\mathrm{n}^{\mathrm{o}}$ 10.861, de 14 de abril de 2004, que institui o Sistema Nacional de Avaliação da Educação Superior (SINAES), tem por finalidade a melhoria da qualidade da educação superior, a orientação da expansão da sua oferta, o aumento permanente da sua eficácia institucional e efetividade acadêmica e social e, especialmente, a promoção do aprofundamento dos compromissos e responsabilidades sociais das instituições de educação superior, por meio da valorização de sua missão pública, da promoção dos valores democráticos, do respeito à diferença e à diversidade, da afirmação da autonomia e da identidade institucional (INEP, 2013).

Também regulamenta através de seu segundo artigo que o SINAES, ao promover a avaliação de instituições, de cursos e de desempenho dos estudantes, deverá assegurar: I avaliação institucional, interna e externa, contemplando a análise global e integrada das dimensões, estruturas, relações, compromisso social, atividades, finalidades e responsabilidades sociais das instituições de educação superior e de seus cursos; II - o caráter público de todos os procedimentos, dados e resultados dos processos avaliativos; III - o respeito à identidade e à diversidade de instituições e de cursos; e IV - a participação do corpo discente, docente e técnico administrativo das instituições de educação superior, e da sociedade civil, por meio de suas representações. E através de seu quinto artigo, que avaliação do desempenho dos estudantes dos cursos de graduação será realizada mediante aplicação do Exame Nacional de Desempenho dos Estudantes (ENADE), que aferirá o desempenho dos estudantes em relação aos conteúdos programáticos previstos nas diretrizes curriculares do respectivo curso de graduação, suas habilidades para ajustamento às exigências decorrentes da evolução do conhecimento e suas competências para compreender temas exteriores ao âmbito específico de sua profissão, ligados à realidade brasileira e mundial e a outras áreas do conhecimento (INEP, 2013).

Conforme apresentado por Polidori (2009), Rothen e Barreyro (2011), em 2008, os indicadores de qualidade do ensino superior passaram a levar em conta o Índice Geral de 
Cursos (IGC), além do Conceito Preliminar de Curso (CPC). Segundo o INEP (2013) o cálculo do IGC inclui a média ponderada dos conceitos preliminares de curso e os conceitos da Coordenação de Aperfeiçoamento de Pessoal de Nível Superior (Capes), que avaliam os programas de pós-graduação das instituições. Enquanto o Índice Geral de Cursos Avaliados da Instituição (IGC) é um indicador que avalia as IES e é resultado da média ponderada dos Conceitos Preliminares de Curso (CPC) da Graduação e do conceito da Capes aplicado aos programas de Pós-graduação, o CPC avalia o rendimento dos alunos, infraestrutura, organização didático-pedagógica e corpo docente. $\mathrm{Na}$ nota do $\mathrm{CPC}$, o desempenho dos estudantes conta $55 \%$ do total, enquanto a infraestrutura e organização didático-pedagógica representam $15 \%$ da nota e o corpo docente, $30 \%$. Na nota dos docentes, a quantidade de doutores pesa $15 \%$ do total, já dedicação integral e mestres representam 7,5\% da nota.

Assim, a melhoria contínua dos processos organizacionais pode ser possibilitada se o processo avaliativo for entendido como sendo uma ferramenta de gestão. Pois uma exigência da legislação vigente, nas diretrizes institucionais, é a possibilidade de mensurar indicadores e melhorar o processo educacional, sem esquecer-se do resultado incidente sobre a qualidade do ensino oferecido ao aluno. Dentro da teoria administrativo-organizacional, existem vários instrumentos que permitem monitorar, detectar e corrigir as ações de gestão e operacionais numa organização, com vistas a melhorar seu desempenho e torná-la mais competitiva (MABA; MARINHO, 2012).

\subsection{ANÁLISE MULTIVARIADA}

Quase toda a metodologia estatística é baseada em análise de variáveis dimensionais finitas ou covariáveis, análise multivariada, modelos de regressão, métodos de agrupamentos e discriminante, não paramétricos, inferências, estimativa de curvas, entre outros (GONZÁLEZ-MANTEIGA, 2008). Para Hair et al. (2010), a análise multivariada refere-se a todos os métodos estatísticos que analisam simultaneamente múltiplas medidas, qualquer análise simultânea de mais de duas variáveis de certo modo pode ser considerada análise multivariada. Desta forma entende-se que muitas técnicas multivariadas são extensões da análise univariada e da análise bivariada. Para Rencher (2002) e Pestana e Gageiro (2005), a análise dos dados pode ser univariada, bivariada ou multivariada conforme o número de variáveis tratadas em simultâneo. $\mathrm{Na}$ análise univariada cada variável é tratada isoladamente e 
deve ser o primeiro passo na exploração dos dados; na bivariada estabelece-se relações entre duas variáveis; e na multivariada o estudo é nas relações entre mais de duas variáveis.

Qualquer análise simultânea de mais de duas variáveis pode ser, de certo modo, considerada como análise multivariada, ou seja, de uma forma bem geral, refere-se a todos os métodos estatísticos que analisam simultaneamente múltiplas medidas em cada indivíduo ou objeto sob investigação, porém, para ser considerado verdadeiramente multivariada todas as variáveis devem ser aleatórias e inter-relacionadas de tal forma que seus diferentes efeitos não podem ser interpretados separadamente de maneira significativa (TABACHNICK;FIDELL, 2007). Outros autores declaram que o propósito da análise multivariada é medir, explicar e predizer o grau de relacionamento entre variáveis (combinação linear de variáveis). Desta forma, a característica multivariada repousa nas múltiplas combinações de variáveis e não somente sobre o número de variáveis ou observações (RENCHER, 2002; TABACHNICK; FIDELL, 2007 e HAIR et al. 2010).

\section{PROCEDIMENTOS METODOLÓGICOS}

Neste trabalho é adotado o estudo de caso como uma estratégia de pesquisa, utilizado de modo exploratório. Segundo Roesch (2007, p.155), estudo de caso "é uma estratégia de pesquisa que busca examinar um fenômeno contemporâneo dentro de seu contexto.” De acordo com Yin (2005), o estudo de caso pode ser utilizado de modo exploratório, com o intuito de levantar questões e hipóteses para futuros estudos por meio de dados qualitativos.

A pesquisa em questão é de natureza aplicada, uma vez que foi realizada para avaliar as mudanças realizadas no instrumento de coleta de dados para avaliação institucional de cursos de uma Instituição de Ensino Superior. A abordagem da pesquisa foi exploratória, uma vez que a coleta de dados ocorreu através de instrumento interno da Instituição. Do ponto de vista do objetivo a pesquisa também foi descritiva, tendo em vista que procurou determinar o grau de satisfação dos acadêmicos (MARCONI; LAKATOS, 2008).

A Instituição em análise têm 14 anos de existência e conta com 16 cursos de graduação na modalidade presencial. A coleta de dados foi efetuada de forma eletrônica através do site da Instituição entre os dias 15/10/2013 à 14/11/2013. Os acadêmicos e professores não tinham obrigatoriedade de preenchimento, ou seja, a coleta foi espontânea. Atualmente são utilizados cinco (5) instrumentos para coleta de dados: (a) aluno avaliando infraestrutura; (b) autoavaliação do aluno e aluno avaliando o professor; (c) professor 
avaliando a infraestrutura; (d) professor avaliando coordenação; (e) professor na sua autoavaliação.

O objeto deste estudo concentra-se no segundo instrumento, ou seja, na autoavaliação do aluno e o aluno avaliando o professor. A escolha deste instrumento se deve em função de ter ocorrido mudanças nas questões em relação ao primeiro semestre de 2013. Após as alterações foi realizado um pré-teste com os DA's (Diretórios Acadêmicos) dos cursos para verificar as mudanças e o entendimento de cada questão.

A escala adotada no instrumento de coleta é de satisfação com dez pontos, onde 1 refere-se a Muito Insatisfeito e 10 a Muito satisfeito. $\mathrm{O}$ instrumento possui 2 construtos: auto avaliação do aluno com 5 itens e o aluno avaliando o professor com 9 itens.

Os softwares utilizados para as análises estatísticas foram IBM SPSS versão 20 e o MINITAB versão 16 , e considerou-se o valor-p $\leq 0,05$ como nível de significância. A análise estatística dos dados partiu inicialmente pela descrição da representatividade da amostra através da utilização de tabelas de distribuições de frequências dos diferentes cursos pesquisados. No estudo da consistência interna foi calculado o Alfa de Cronbach ( $\alpha$ ) para cada um dos construtos do instrumento, bem como, por curso. Na análise fatorial foi utilizado o teste de esfericidade de Bertlett e KMO, para extração foi utilizado análise de componentes principais e para determinação da quantidade de construtos foi utilizado o critério de Kaiser com autovalor 1 e a rotação Varimax. Na identificação de associação entre os fatores e os cursos, foi calculado o coeficiente de correlação linear de Pearson (r). Para avaliar a existência de diferenças significativas entre as médias dos cursos foi utilizada a Análise de Variância (ANOVA) e, por fim, foi realizada a Análise de Cluster que permite agrupar os sujeitos que realizaram a avaliação.

\section{ANÁLISE E DISCUSSÃO DOS RESULTADOS}

Nesta seção são apresentados os resultados da avaliação de cursos de uma determinada Instituição de Ensino superior do Rio Grande do Sul, referida por "Instituição A". A avaliação dos cursos está presente na instituição desde seu início, sendo que a coleta de dados ocorre semestralmente. $\mathrm{O}$ estudo desenvolveu-se a partir da necessidade de entender o comportamento do instrumento de coleta de dados uma vez que no ano de 2013 o instrumento de coleta sofreu alterações no que diz respeito à autoavaliação (acadêmico) e a avaliação do professor por parte do acadêmico. Vale salientar que o estudo também terá impacto para 
auxiliar alguns professores em discutir suas práticas pedagógicas e avaliar o trabalho coletivo presente na Instituição. Todo o gerente deve encontrar maneiras de acompanhar os efeitos que as mudanças internas impõem na sua organização. Em uma Instituição de Ensino esta realidade não é diferente os gestores (coordenadores) devem se adequar e analisar mudanças, desta forma, o estudo visa auxiliar também no planejamento de necessidades futuras.

Por fim, esta seção visa demonstrar a utilização de métodos quantitativos na análise do instrumento de avaliação de cursos na modalidade presencial, bem como, descrever a amostra, analisar a consistência interna do instrumento, avaliar a correlação linear, observar a análise fatorial, a análise de variância e a Análise de Cluster.

\subsection{ANÁLISE DA REPRESENTATIVIDADE DA AMOSTRA}

A coleta foi realizada com 16 cursos de graduação na modalidade presencial da Instituição em estudo. Cada aluno responde o instrumento para todas as disciplinas em que se encontra matriculado, uma vez que, a avaliação é realizada por disciplina. Os cursos em análise foram numerados de 1 ao 16 e a representatividade destes cursos no número total de alunos e o percentual de respondentes pode ser visto na Tabela 1. Vale salientar que o processo de avaliação é totalmente espontâneo.

Tabela 1 Descrição geral dos cursos.

\begin{tabular}{l|c|c}
\hline \multirow{2}{*}{ Cursos } & \multicolumn{2}{|c}{ Representatividade } \\
\cline { 2 - 3 } & $\begin{array}{c}\text { (\% de alunos no sobre o total } \\
\text { da Instituição) }\end{array}$ & Respondentes no curso \\
\hline Curso 1 & $27,1 \%$ & $38 \%$ \\
\hline Curso 2 & $5,4 \%$ & $47,5 \%$ \\
\hline Curso 3 & $5,5 \%$ & $42 \%$ \\
\hline Curso 4 & $6,4 \%$ & $40,6 \%$ \\
\hline Curso 5 & $10,8 \%$ & $31 \%$ \\
\hline Curso 6 & $5,8 \%$ & $45,8 \%$ \\
\hline Curso 7 & $3,5 \%$ & $68 \%$ \\
\hline Curso 8 & $1,5 \%$ & $66 \%$ \\
\hline Curso 9 & $2,3 \%$ & $45 \%$ \\
\hline Curso 10 & $4,9 \%$ & $49,8 \%$ \\
\hline Curso 11 & $4,6 \%$ & $46,3 \%$ \\
\hline Curso 12 & $4,8 \%$ & $37 \%$ \\
\hline Curso 13 & $2,2 \%$ & $38 \%$ \\
\hline Curso 14 & $3,3 \%$ & $26 \%$ \\
\hline Curso 15 & $11,2 \%$ & $41,2 \%$ \\
\hline Curso 16 & $0,6 \%$ & $71,3 \%$ \\
\hline
\end{tabular}

O total de questionários respondidos foi de 8.854 , lembrando que o mesmo aluno pode responder a mais de um questionário uma vez que o instrumento é aplicado por disciplina 
matriculada. Observa-se que o curso com maior participação foi o curso 16 com 71,3\% e com menor participação foi o curso 14 com 26\%. Para as análises posteriores os cursos 7 e 8 (bacharelado e licenciatura) serão agrupados pois as disciplinas cursadas pelos alunos são, em sua maioria, as mesmas e como a avaliação é realizada por disciplina não foi possível separálos.

\subsection{ANÁLISE DE CONSISTÊNCIA INTERNA DO INSTRUMENTO}

$\mathrm{Na}$ análise de consistência interna foi utilizado o Alfa de Cronbach ( $\alpha$ ) para a validação dos itens, analisando a consistência das variáveis e confiabilidade dos construtos. Neste estudo considera-se o critério de $A l f a$ superior a 0,7 como aceitável (RENCHER, 2002; e HAIR et al., 2010). O valor do Alfa de Cronbach obtido foi de $\alpha=0,959$ em análise dos dois construtos, resultando numa ótima consistência interna do instrumento. Devido às características do instrumento utilizado, o qual as questões representam dimensões distintas, o coeficiente Alpha de Cronbach foi calculado, também, para cada construto e para cada curso.

$\mathrm{Na}$ análise dos resultados apresentados observa-se que mesmo separando por curso o instrumento apresenta uma consistência interna ótima, pois todos os cursos apresentaram Alfa de Cronbach ( $\alpha$ ) acima de 0,94. Quando realizada a análise separando por constructo a auto avaliação apresentou o menor Alfa de Cronbach $(\alpha)=0,863$ com o curso 9 e o aluno avaliando o professor o maior Alfa de Cronbach $(\alpha)=0,977$ com os cursos 4 e 14. Assim, valida-se a confiabilidade da escala utilizada.

\subsection{ANÁLISE FATORIAL DO INSTRUMENTO}

Neste tópico o que se busca é a confirmação de que o instrumento aplicado realmente apresenta-se com dois construtos, o primeiro com 5 variáveis e o segundo com 9 variáveis. Para tanto foi utilizada a análise fatorial exploratória onde assume-se que todos as variáveis são relacionadas a todos os construtos (HAIR et al., 2010). Também pode-se afirmar que foi realizada uma análise fatorial confirmatória pois o instrumento foi aplicado com a separação de dois construtos (Auto avaliação e Aluno avaliando o professor). Para Hair et al. (2010) a principal diferença entre a análise fatorial confirmatória e a análise fatorial exploratória é o controle sobre as variáveis que descrevem cada fator. $\mathrm{Na}$ análise fatorial exploratória, todas as variáveis apresentam cargas fatoriais em todos os fatores, já a análise fatorial confirmatória o pesquisador especifica que variáveis descrevem cada constructo. 
Os critérios para aplicação da análise fatorial, segundo Hair et al. (2010), são que o número de amostras seja no mínimo 5 vezes maior que o número de itens avaliados, o que no estudo foi atendido. O autor também salienta que o KMO deve ser superior a 0,5 e Bartlett's Test of Sphericity deve ser inferior à 0,05 . Outro ponto a ser analisado na avaliação do Instrumento é a comunalidade que se refere a quantia total de variância que uma variável compartilha com todas as outras variáveis da pesquisa, onde deve-se eliminar valores abaixo de 0,5 . Neste estudo pode-se observar na Tabela 2 os resultados da análise fatorial onde todos os índices KMO e a esfericidade de Bartlett estão dentro dos níveis aceitáveis com variância explicada pelos dois fatores de 79,94\%.

Também como meio de validar um instrumento, Koufteros (1999) sugere a realização da ratificação dos construtos por meio da análise intrablocos, com o uso dos parâmetros de unidimensionalidade do conjunto de variáveis observáveis dentro de cada fator. Neste sentido foi realizada uma análise fatorial intrablocos, ou seja, com os fatores separados, onde a variância explicada pelo fator 1 (auto avaliação) foi de 75,04\% e pelo fator 2 (aluno avaliando o professor) foi de $81,98 \%$, reforçando a validação do instrumento. Também não foram identificadas comunalidades baixas, que poderia justificar a exclusão de uma variável observável.

\subsection{ANÁLISE DESCRITIVA DE CADA VARIÁVEL POR CURSO}

Após a validação do instrumento através da consistência interna e da confirmação dos fatores do instrumento através da análise fatorial pode-se avaliar e analisar descritivamente os resultados da coleta. $\mathrm{Na}$ análise dos fatores evidencia-se que a média Geral do Fator 1, autoavaliação, ficou em 8,45 representando uma média alta. Analisando individualmente cada variável observada dentro deste fator observa-se que a variável A1 (Quanto à sua frequência e aproveitamento do horário de aula no desenvolvimento da disciplina) ficou com a maior média o que demonstra um aproveitamento dos horários das aulas; e a variável A5 (Quanto à sua frequência à biblioteca e retirada de livros e periódicos) ficou com a menor média de 7,96, o que demonstra que no quesito frequência na biblioteca deve ser estimulado junto aos professores em ações de desenvolvimento para o aluno.

Para o Fator 2, aluno avaliando o professor, constata-se que a média geral foi de 8,54 também representando uma média alta. Partindo-se para a análise individual a variável P5 (Quanto à demonstração de conhecimento dos conteúdos da sua disciplina) apresenta a maior 


\section{ANÁLISE DO INSTRUMENTO DE AVALIAÇÃO DE CURSOS EM UMA INSTITUIÇÃO DE ENSINO

média de 8,75, já a variável P4 (Quanto ao estabelecimento das relações entre teoria e prática da disciplina) ficou com a menor média de 8,39. Analisando os cursos observa-se que as médias ficam muito próximas, sendo que para o primeiro fator a menor média ficou em 8,18 e a maior média de 9,04, respectivamente, curso 6 e curso 14 . Na análise do segundo fator observam-se médias maiores onde os cursos 11 e 7 apresentaram, respectivamente, menor $(8,09)$ e maior $(8,84)$ média.

Tabela 2 Analise Fatorial e Comunalidade das Variáveis.

\begin{tabular}{|c|c|c|c|c|c|c|}
\hline $\begin{array}{c}\text { Fator/ } \\
\text { Variável } \\
\text { Latente }\end{array}$ & Média & $\begin{array}{l}\text { Desvio } \\
\text { Padrão }\end{array}$ & $\begin{array}{l}\text { Alfa de } \\
\text { Cronbach }\end{array}$ & Variáveis Observáveis & $\begin{array}{c}\text { Cargas } \\
\text { Fatoriais }\end{array}$ & Comunalidade \\
\hline \multirow{5}{*}{$\begin{array}{l}\text { Fator } 1 \\
\text { Auto } \\
\text { avaliação }\end{array}$} & \multirow{5}{*}{8,45} & \multirow{5}{*}{1,48} & \multirow{5}{*}{0,916} & $\begin{array}{l}\text { A1) Quanto à sua frequência e aproveitamento do } \\
\text { horário de aula no desenvolvimento da disciplina. }\end{array}$ & 0,806 & 0,772 \\
\hline & & & & $\begin{array}{l}\text { A2) Quanto ao seu acesso e acompanhamento do } \\
\text { plano de ensino (Objetivos, metodologia, critérios } \\
\text { de avaliação e bibliografias). }\end{array}$ & 0,802 & 0,789 \\
\hline & & & & $\begin{array}{l}\text { A3) Quanto à sua participação e contribuição em } \\
\text { sala de aula nas atividades desenvolvidas na } \\
\text { disciplina. }\end{array}$ & 0,830 & 0,798 \\
\hline & & & & $\begin{array}{l}\text { A4) Quanto ao tempo dedicado aos estudos extra } \\
\text { sala de aula. }\end{array}$ & 0,861 & 0,759 \\
\hline & & & & $\begin{array}{l}\text { A5) Quanto à sua frequência à biblioteca e retirada } \\
\text { de livros e periódicos. }\end{array}$ & 0,800 & 0,634 \\
\hline \multirow{9}{*}{$\begin{array}{l}\text { Fator } 2 \\
\text { Aluno } \\
\text { avaliando } \\
\text { professor }\end{array}$} & \multirow{9}{*}{8,54} & \multirow{9}{*}{1,82} & \multirow{9}{*}{0,972} & $\begin{array}{l}\text { P1) Quanto ao aproveitamento do horário de aula } \\
\text { no desenvolvimento da disciplina. }\end{array}$ & 0,823 & 0,782 \\
\hline & & & & $\begin{array}{l}\text { P2) Quanto à apresentação e cumprimento do } \\
\text { plano de ensino. }\end{array}$ & 0,843 & 0,802 \\
\hline & & & & $\begin{array}{l}\text { P3) Quanto ao planejamento e desenvolvimento } \\
\text { das aulas (Alguns exemplos: seminários, aulas } \\
\text { expositivas, trabalhos em grupo, estudo de casos, } \\
\text { etc.). }\end{array}$ & 0,869 & 0,843 \\
\hline & & & & $\begin{array}{l}\text { P4) Quanto ao estabelecimento das relações entre } \\
\text { teoria e prática da disciplina. }\end{array}$ & 0,876 & 0,839 \\
\hline & & & & $\begin{array}{l}\text { P5) Quanto à demonstração de conhecimento dos } \\
\text { conteúdos da sua disciplina. }\end{array}$ & 0,877 & 0,816 \\
\hline & & & & $\begin{array}{l}\text { P6) Quanto ao incentivo à busca de diferentes } \\
\text { materiais de estudos: livros e artigos em periódicos } \\
\text { especializados para aprofundamento do tema } \\
\text { tratado em aula. }\end{array}$ & 0,850 & 0,815 \\
\hline & & & & $\begin{array}{l}\text { P7) Quanto à clareza dos critérios de avaliação } \\
\text { adotados para atingir os objetivos da disciplina. }\end{array}$ & 0,869 & 0,824 \\
\hline & & & & $\begin{array}{l}\text { P8) Quanto à contextualização dos conhecimentos } \\
\text { da disciplina com questões da realidade brasileira } \\
\text { e mundial. }\end{array}$ & 0,884 & 0,850 \\
\hline & & & & $\begin{array}{l}\text { P9) Quanto à comunicação entre professor e aluno } \\
\text { durante a construção do conhecimento da área em } \\
\text { estudo. }\end{array}$ & 0,871 & 0,806 \\
\hline \multicolumn{5}{|c|}{ Kaiser-Meyer-Olkin (KMO) } & \multicolumn{2}{|l|}{0,958} \\
\hline \multicolumn{5}{|c|}{ Teste de Esfericidade Bartlett (*Nível de significância $\mathrm{p}<0,001$ ) } & \multicolumn{2}{|l|}{0,000} \\
\hline \multicolumn{5}{|c|}{ Variância Explicada } & \multicolumn{2}{|l|}{$79,94 \%$} \\
\hline
\end{tabular}


Numa análise geral, como pode ser observado pelo exposto no decorrer deste tópico e conforme Tabela 2, ambos os fatores pesquisados nos diferentes cursos apresentaram notas de satisfação acima de 8,00 demonstrando que o trabalho docente, na percepção do aluno, está adequado.

\subsection{ANÁLISE DA INFLUÊNCIA DAS VARIÁVEIS OBSERVÁVEIS NOS CURSOS}

A fim de verificar a existência de relação entre as variáveis observáveis e os fatores, calculou-se o Coeficiente de Correlação de Pearson. De acordo com Pestana e Gageiro (2005), o "coeficiente de correlação R de Pearson é uma medida de associação linear entre variáveis quantitativas e varia entre -1 e 1". A existência da correlação indica que a intensidade de um fenômeno é acompanhada tendencialmente por outro, embora eles não sejam indissoluvelmente ligados. Por convenção, os autores sugerem que $\mathrm{R}<0,2=$ associação muito baixa; $R$ entre 0,2 e 0,39 = associação baixa; $R$ entre 0,4 e 0,69 = associação moderada; R entre 0,7 e 0,89= associação alta; e R entre 0,9 e 1 = associação muito alta.

Ao analisar-se os dados do estudo a associação mostra-se aceitável para todas as variáveis analisadas ao nível de significância de 0,01. A correlação entre as variáveis observáveis do Fator 2 (aluno avaliando professor) todas obtiveram associação alta o que mostra coerência e consistência nas questões do instrumento. Ao analisar os coeficientes da variável A5 em relação a todas as variáveis do Fator 2 evidencia-se os menores índices de associação. O que demonstra analisando a variável A5 "Quanto à sua frequência à biblioteca e retirada de livros e periódicos", que o aluno tem consciência que o aprendizado também é de sua responsabilidade, pois a média desta variável foi a menor e também apresentou uma carga fatorial menor do que as demais variáveis observadas. Aqui pode-se perceber um ponto a ser melhorado, onde os gestores dos cursos devem intervir junto aos professores, buscando, incentivar práticas para que o acadêmico busque com maior frequência a utilização da biblioteca melhorando a construção do conhecimento da área em estudo.

\subsection{ANÁLISE DE VARIÂNCIA DOS CURSOS}

O próximo passo na análise dos resultados é investigar a influência dos cursos sobre os respondentes, neste caso, o intuito é definir se existe diferenças significativas entre as médias de satisfação dos cursos, pois em caso afirmativo as ações podem ser individualizadas, caso contrário as ações de melhoria por parte dos gestores, pode ser de forma generalizada. Desta 


\section{ANÁLISE DO INSTRUMENTO DE AVALIAÇÃO DE CURSOS EM UMA INSTITUIÇÃO DE ENSINO \\ SUPERIOR DA SERRA GAÚCHA \\ DOI: http://dx.doi.org/10.5007/1983-4535.2016v9n2p301}

forma, realizou-se a ANOVA para os fatores, obtendo-se os seguintes resultados de significância: (i) Autoavaliação $(0,00)$ e (ii) Aluno avaliando o professor $(0,00)$. Diante destes resultados, afirma-se que, nesta amostra, há diferença significativas em relação aos dois fatores nas respostas dos diferentes cursos. Porém, mesmo existindo diferenças entre as médias dos cursos foi possível evidenciar que a satisfação dos alunos, nas diferentes variáveis, apresenta-se com valores acima de 8,00 caracterizando uma alta satisfação com o trabalho docente.

\subsection{ANÁLISE DO COMPORTAMENTO DAS RESPOSTAS DENTRO DOS CURSOS}

Uma vez que os dados apresentaram diferenças nas médias dos fatores entre os cursos, conforme a ANOVA, optou-se por realizar uma análise de Cluster para identificar grupos de respondentes nos cursos com avaliações semelhantes entre si e diferentes entre grupos. Isto para dar subsídios para os gestores dos cursos para verificar agrupamentos entre os respondentes. Na Tabela 3 apresentam-se os clusters e suas caracterizações.

Tabela 3 Análise dos clusters dentro dos cursos.

\begin{tabular}{|c|c|c|c|c|c|c|c|}
\hline \multirow[b]{2}{*}{ Curso } & \multirow[b]{2}{*}{ Cluster } & \multicolumn{3}{|c|}{ Auto avaliação } & \multicolumn{3}{|c|}{ Aluno avaliando o professor } \\
\hline & & $\begin{array}{l}\text { \% do } \\
\text { cluster }\end{array}$ & Média & Desvio & $\begin{array}{c}\text { \% do } \\
\text { cluster }\end{array}$ & Média & Desvio \\
\hline \multirow{3}{*}{ Curso 1} & Média baixa & $29,7 \%$ & 6,696 & 1,2368 & $19,5 \%$ & 6,09 & 1,5458 \\
\hline & Média & $36,1 \%$ & 8,261 & 0,3917 & $29,6 \%$ & 8,179 & 0,3818 \\
\hline & Média alta & $34,2 \%$ & 9,407 & 0,4364 & $51,0 \%$ & 9,487 & 0,4509 \\
\hline \multirow{3}{*}{ Curso 2} & Média baixa & $10,1 \%$ & 6,031 & 1,334 & $26,7 \%$ & 5,688 & 1,9491 \\
\hline & Média & $43,0 \%$ & 7,398 & 0,6517 & $46,7 \%$ & 8,559 & 0,5347 \\
\hline & Média alta & $46,9 \%$ & 9,145 & 0,5989 & $26,7 \%$ & 9,856 & 0,1939 \\
\hline \multirow{3}{*}{ Curso 3} & Média baixa & $31,0 \%$ & 6,825 & 1,239 & $37,3 \% * *$ & 6,949 & 1,44 \\
\hline & Média & $50,7 \%$ & 8,75 & 0,555 & $39,2 \%$ & 9,151 & 0,364 \\
\hline & Média alta & $18,3 \%$ & $10 * *$ & 0 & $23,5 \% *$ & $10 * *$ & 0 \\
\hline \multirow{3}{*}{ Curso 4} & Média baixa & $34,6 \%$ & 6,768 & 1,087 & $12,5 \%$ & 4,302 & 1,8256 \\
\hline & Média & $50,2 \%$ & 8,635 & 0,532 & $27,0 \%$ & 7,66 & 0,6164 \\
\hline & Média alta & $15,2 \%$ & $10 * *$ & 0 & $60,5 \%$ & 9,477 & 0,4996 \\
\hline \multirow{3}{*}{ Curso 5} & Média baixa & $29,1 \%$ & 6,448 & 1,381 & $13,1 \%$ & 4,875 & 1,8219 \\
\hline & Média & $48,8 \%$ & 8,783 & 0,542 & $41,8 \%$ & 8,296 & 0,7472 \\
\hline & Média alta & $22,1 \%$ & $10 * *$ & 0 & $45,1 \%$ & 9,901 & 0,1885 \\
\hline \multirow{3}{*}{ Curso 6} & Média baixa & $10,9 \%$ & 5,423 & 1,4936 & $7,8 \%$ & 4,692 & 1,4346 \\
\hline & Média & $55,4 \%$ & 7,84 & 0,6826 & $39,0 \%$ & 7,853 & 0,6606 \\
\hline & Média alta & $33,7 \%$ & 9,406 & 0,5245 & $53,2 \%$ & 9,439 & 0,4855 \\
\hline \multirow{3}{*}{ Curso 7 e8 } & Média baixa & $\begin{array}{c}45,67 \% * \\
*\end{array}$ & 7,475 & 1,4206 & $32,45 \%$ & $7,205 * *$ & 1,677 \\
\hline & Média & $31,42 \%$ & 8,872 & 0,3025 & $38,62 \%$ & 9,208 & 0,366 \\
\hline & Média alta & $22,91 \%$ & 9,908 & 0,1721 & $28,93 \%$ & $10 * *$ & 0 \\
\hline \multirow{3}{*}{ Curso 9} & Média baixa & $43,9 \%$ & 7,397 & 0,7912 & $21,1 \%$ & 5,934 & 1,5234 \\
\hline & Média & $41,3 \%$ & 8,902 & 0,466 & $26,7 \%$ & 8,262 & 0,3674 \\
\hline & Média alta & $14,9 \% *$ & $10 * *$ & 0 & $52,1 \%$ & 9,711 & 0,3879 \\
\hline
\end{tabular}




\begin{tabular}{l|l|c|c|c|c|c|c}
\hline \multirow{3}{*}{ Curso 10 } & Média baixa & $39,6 \%$ & 7,25 & 0,9075 & $8,6 \%$ & 4,293 & 1,5178 \\
\cline { 2 - 7 } & Média & $44,7 \%$ & 8,797 & 0,507 & $35,1 \%$ & 7,978 & 0,638 \\
\cline { 2 - 7 } & Média alta & $15,7 \%$ & $10^{* *}$ & 0 & $56,3 \%$ & 9,547 & 0,438 \\
\hline \multirow{3}{*}{ Curso 11 } & Média baixa & $30,5 \%$ & 6,459 & 1,5448 & $9,8 \%$ & 3,19 & 1,77 \\
\cline { 2 - 7 } & Média & $35,7 \%$ & 8,099 & 0,5226 & $60,7 \%$ & 7,863 & 1,046 \\
\cline { 2 - 8 } & Média alta & $33,8 \%$ & 9,462 & 0,4741 & $29,5 \%$ & 9,811 & 0,268 \\
\hline \multirow{3}{*}{ Curso 12 } & Média baixa & $50,2 \%$ & $8,012^{* *}$ & 0,9918 & $5,7 \% *$ & 3,373 & 1,8883 \\
\cline { 2 - 8 } & Média & $26,0 \%$ & 9,197 & 0,2636 & $52,7 \%$ & 8,43 & 0,787 \\
\cline { 2 - 8 } & Média alta & $23,8 \%$ & $10^{* *}$ & 0 & $41,6 \%$ & 9,949 & 0,1272 \\
\hline \multirow{3}{*}{ Curso 13 } & Média baixa & $45,1 \%$ & 7,282 & 1,27 & $14,1 \%$ & 5,383 & 1,5974 \\
\cline { 2 - 8 } & Média & $36,4 \%$ & 8,992 & 0,45 & $22,3 \%$ & 7,657 & 0,4822 \\
\cline { 2 - 8 } & Média alta & $18,4 \%$ & $10^{* *}$ & 0 & $63,6 \% * *$ & $9,358^{*}$ & 0,5187 \\
\hline \multirow{3}{*}{ Curso 150 14 } & Média baixa & $11,2 \%$ & 5,447 & 2,501 & $6,3 \%$ & $2,046 *$ & 1,692 \\
\cline { 2 - 8 } & Média & $51,2 \%$ & 8,8 & 0,511 & $43,8 \%$ & 8,092 & 1,122 \\
\cline { 2 - 8 } & Média alta & $37,6 \%$ & $10^{* *}$ & 0 & $49,9 \%$ & 9,938 & 0,152 \\
\hline & Média baixa & $15,0 \%$ & 6,165 & 1,3954 & $6,6 \%$ & 3,779 & 1,3675 \\
\cline { 2 - 8 } & Média alta & $24,8 \%$ & 7,65 & 0,4283 & $54,6 \%$ & 8,147 & 0,9864 \\
\hline \multirow{3}{*}{ Curso 16 } & $60,1 \% * *$ & $9,057^{*}$ & 0,5999 & $38,8 \%$ & 9,848 & 0,2232 \\
\hline & Média baixa & $8,3 \% *$ & $5,24^{*}$ & 1,3221 & $15,0 \%$ & 6,605 & 1,2779 \\
\cline { 2 - 8 } & Média alta & $50,0 \%$ & 8,1 & 0,3591 & $35,0 \%$ & 8,307 & 0,2917 \\
\hline
\end{tabular}

(OBS: As células em destaque * valor mais baixo e $* *$ valor mais alto)

Conforme Hair et al. (2010), a análise de Cluster é uma técnica multivariada de interdependência, que possibilita combinar objetos que tenham alta homogeneidade interna (dentro do conglomerado) e alta heterogeneidade externa (entre conglomerados). A análise de agrupamentos tem o objetivo de agrupar respondentes semelhantes ou casos com perfis similares em um dado conjunto de características. A Análise de Clusters pretende organizar um conjunto de casos em grupos homogêneos, de tal modo que os indivíduos pertencentes a um grupo são o mais semelhante possível entre si e diferenciados dos restantes. Esta análise procura classificar um conjunto de objetos (indivíduos, produtos, etc.) em grupos ou categorias usando os valores observados das variáveis, sem que seja necessário definir critérios que classificam os dados que integram determinado grupo.

Desta forma, o objetivo aqui foi identificar e agrupar os respondentes a fim de verificar algum comportamento semelhante dos alunos das diferentes áreas. Considerou-se mais adequado realizar análise separada pelos dois fatores/construtos do instrumento aplicado, uma vez que isto já foi testado na análise fatorial. A Análise de Cluster foi realizada para agrupar os sujeitos pesquisados conforme avaliação que fizeram sobre os cursos. Considerouse mais adequada a retenção de três agrupamentos, já que estes possibilitaram melhor interpretação dos dados, tendo em vista maior heterogeneidade entre estes. Ressalta-se que, para a análise da avaliação optou-se pela análise estratificada por curso, ou seja, foram gera- 
dos os três Custers para cada curso, onde cada um corresponde a um tipo de resultado: Cluster 1 (Média baixa), Cluster 2 (Média) e Cluster 3 (Média alta). O método de separação utilizado foi o Ward e para determinação do centróide foi utilizado a medida euclidiana.

$\mathrm{Na}$ análise é possível evidenciar que o construto "autoavaliação" apresenta o cluster 1 (média baixa) com médias entre 5,24 e 8,01 e frequências de respostas entre 8,3\% e 45,67\%; já para o cluster 3 (média alta) as respostas se concentraram com médias entre 9,06 e 10 e frequências entre $14,9 \%$ e $60,1 \%$. De modo semelhante pode-se analisar o construto "aluno avaliando o professor" onde o cluster 1 (média baixa) apresentou médias entre 2,05 e 7,21 e frequência entre 5,7\% e 37,3\%; para o cluster 3 (média alta) as médias dos cursos ficaram entre 9,36 e 10 e as frequências de respostas entre $23,5 \%$ e $63,6 \%$. Assim, pode-se destacar que, de maneira geral, todos os cursos apresentam notas de satisfação altas e com maior concentração dos respondentes no cluster 2 e cluster 3 , respectivamente média e média alta de satisfação, o que confirma as análises já relatadas anteriormente pela estatística descritiva, onde, na percepção do aluno, a satisfação com o trabalho docente mostra-se adequada levando em consideração as variáveis observáveis deste estudo.

\section{CONSIDERAÇÕES FINAIS}

O estudo foi realizado em uma instituição de ensino superior localizada no estado do Rio Grande do Sul, que por motivos estratégicos foi denominada ao longo deste estudo como Instituição A. O estudo baseou-se nos resultados do instrumento de avaliação dos cursos de graduação realizado no segundo semestre de 2013. Vale reforçar que as condições econômicas e de mercado para todos os tipos de negócio variam ao longo do tempo, e os gestores das empresas devem acompanhar os efeitos que essas mudanças refletem sob suas organizações. No ramo da educação não é diferente, para que uma Instituição seja saudável financeiramente é necessário que a equipe gestora tenha ferramentas que forneçam subsídios para a tomada de decisão (VIDOR; WERNER; MARTINS, 2011). Uma dessa ferramentas é a avaliação dos cursos onde o gestor pode tomar ações a partir do grau de satisfação do público acadêmico.

Para Sobrinho (1995), deve-se compreender a universidade como um conjunto de processos e relações que se produzem em seu cotidiano, não sendo, portanto, uma realidade pronta e acabada. A faculdade é uma instituição social de caráter essencialmente pedagógico, e, compreendê-la dessa forma, ajuda a perceber melhor a sua avaliação. Assim, o objeto deste 
estudo foi analisar a consistência interna e os resultados do instrumento de avaliação dos cursos aplicados a uma instituição de ensino da Serra Gaúcha, também fez uso de técnicas da análise multivariada, para validação do instrumento e análise da satisfação do público que responde sob a ótica de dois fatores: a auto avaliação e o aluno avaliando o professor. Vale salientar que o instrumento analisado é um dos aplicados na instituição e diz respeito a avaliação pedagógica e relação professor aluno, os demais instrumentos de avaliação de infraestrutura e dos serviços não foram objeto deste estudo. A escolha deste instrumento para estudo ocorreu em função de mudanças realizadas nas questões/variáveis observáveis do instrumento no segundo semestre de 2013.

As conclusões deste estudo estão estruturadas em duas perspectivas distintas. A primeira, conclui sobre a aplicação das ferramentas utilizadas para análise estatística deste estudo e a segunda perspectiva, foca os objetivos do estudo. Quanto as ferramentas utilizadas para avaliar o instrumento o Alfa de Cronbach obtido foi de 0,959 resultando numa ótima consistência interna do instrumento. A análise fatorial confirmou os dois fatores (autoavaliação e aluno avaliando o professor) atribuídos ao instrumento com variância explicada de 79,94\%. Na análise de correlação as variáveis observáveis com maior associação, novamente se dividiram em dois grupos (fatores) confirmando e validando novamente o instrumento. Quanto aos objetivos do trabalho, a primeira contribuição do estudo foi conscientização da equipe quanto a importância da coleta de dados e análise das mudanças propostas. Também foi possível verificar que o nível de satisfação nos diferentes cursos está acima de 8,00, o que demonstra que o trabalho docente está adequado na percepção do aluno. De um modo geral, é possível concluir que, no entender dos alunos, os dois fatores e todas as variáveis foram avaliadas como satisfatórias. Destaca-se que a Análise de Cluster foi importante pois a Tabela 2 construída em função dos cursos e com a concentração de alunos em três faixas distintas (média baixa, média e média alta) pode se traduzir, por parte dos gestores, em ações de melhorias individualmente para cada curso. Em resumo tem-se assim um instrumento que vem auxiliar a instituição, como uma ferramenta que permite a avaliação dos cursos, apresentando coerência interna e adequação às recomendações do Ministério da Educação.

Do estudo realizado, bem como das conclusões obtidas, sugere-se estudos para dar continuidade a este trabalho bem como para ampliar sua abrangência. Destes, destacam-se, dois: o primeiro consiste em analisar o banco de dados coletados no primeiro semestre de 
2013 realizando as análises semelhantes as aplicadas neste estudo. O segundo é realizar uma comparação entre os dois semestres avaliando se houve impacto significativo das mudanças na avaliação geral dos cursos.

\section{REFERÊNCIAS}

BORTOLOTTI, S. L. V.; JUNIOR, F. J. M.; BORNIA, A. C.; JÚNIOR, A. F. S.; ANDRADE, D. F. Avaliação do nível de satisfação de alunos de uma instituição de ensino superior uma aplicação da Teoria da Resposta ao Item. Gestão \& Produção, São Carlos, v. 19, n. 2, p. 287-302, 2012.

GIANOTTI, S. S. C. Avaliação Estratégica: Um modelo de Gestão Institucional integrada a Gestão Estratégica de Instituições de Ensino Superior. Tese de Doutorado. Porto Alegre: UFRGS, 2004.

GONZÁLEZ-MANTEIGA, W. F. Ferraty and P. Vieu: Nonparametric functional data analysis: theory and practice. Computacional Statistics, 23, p. 341-342, 2008.

HAIR, J. F., Jr.; ANDERSON, R. E.; BABIN, B. J.; BLACK, W.C. Multivariate Data Analysis. Seventh Edition. Pearson Prentice Hall, 2010.

HAIR, J. F., Jr.; ANDERSON, R. E.; TATHAM, R. L.; BLACK, W.C. Análise multivariada de dados. 5. ed. Porto Alegre: Bookman, 2005.

KOUFTEROS, X. A. Testing a model of pull production: a paradigm for manufacturing research using structural equation modeling. Journal of Operations Management, v. 17 p.467- 488, 1999.

MABA, E. G.; MARINHO, S. V. A Autoavaliação Institucional no processo de Tomada de decisão em IES: Estudo de caso das Faculdades Senac/SC. Avaliação, Campinas: Sorocaba, SP, v.17, n.2, p. 455-480, 2012.

MAlHOtRA, N. K. Pesquisa de Marketing. Porto Alegre: Bookman, 2006.

MARCONI, M. A.; LAKATOS, E. M. Fundamentos de Metodologia Científica. $6^{\mathrm{a}}$ ed. São Paulo: Atlas, 2008.

MEYER Jr., V.; MURPHY, J. P. Dinossauros, gazelas e tigres: novas abordagens da administração universitária, um diálogo Brasil EUA. 2 ed. ampliada. Florianópolis: Insular, 2003.

MEC. MINISTÉRIO DA EDUCAÇÃO DO BRASIL. Disponível em: $<$ http://portal.mec.gov.br/index.php>. Acesso em: 20 dez. 2013.

MICHAEL, S. O. In search of universal principles of higher education management andapplicability to Moldavian higher education system. The International Journal of Educational Management, v. 18, n. 2, p. 118-137, 2004. 
PALACIO, A. B.; MENESES, G. D.; PÉREZ, P. J. P. The configuration of the university image and its relationship with the satisfaction of students. Journal of Educational Administration, v. 40, n. 5, p. 486-505, 2002.

PEIXOTO, M. C. L. A Avaliação Institucional nas Universidades Federais e as Comissões Próprias de Avaliação. Avaliação, Campinas: Sorocaba, SP, v. 14, n.1, p. 9-28, 2009.

PESTANA, M. H.; GAGEIRO, J. N. Análise de dados para Ciências Sociais. $4^{\circ}$ Edição. Edições Sílabo, Lisboa, 2005.

POLIDORI, M. M. Políticas de Avaliação da Educação Superior Brasileira: Provão, SINAES, IDD, CPC, IGC e outros índices. Avaliação, Campinas: Sorocaba, SP, v.14, n. 2, p.439-452, 2009.

RENCHER, A. C. Methods of multivariate analysis. 2nd ed. John Wiley \& Sons, 2002.

RIBEIRO, E. A. As atuais políticas públicas de avaliação para a educação superior e os impactos na configuração do trabalho docente. Avaliação, Campinas; Sorocaba, SP, v. 17, n.2, p. 299-316, 2012.

ROESCH, Sylvia Maria Azevedo. Projeto de Estágio e de Pesquisa em Administração: Guia para Estágios, Trabalhos de Conclusão, Dissertações e Estudos de Caso. São Paulo: Atlas, 2007.

ROTHEN, J. C.; BARREYRO, G. B. Avaliação da Educação Superior no Segundo Governo Lula: "Provão II" ou a reedição de velhas práticas? Educ. Soc., Campinas, v.32, n.114, p. 21-38, 2011.

SOBRINHO, J. D. Universidade: processos de socialização e processos pedagógicos. In: Avaliação institucional: teoria e experiências. São Paulo: Cortez, 1995.

TABACHNICK, B. G.; FIDELL, L. S. Using Multivariate Statistics. Pearson Education. Inc, Fifth Edition, 2007.

TAVARES, M. G. M.; OLIVEIRA, M. A. A.; SEIFFERT, O. M. L. B. Avaliação da educação superior. Ensaio: Avaliação e Políticas Públicas em Educação, Rio de Janeiro, v. 19, n. 71, p. 233-258, 2011.

VIDOR, G.; WERNER, L.; MARTINS, V. L. M. Direcionamento de investimentos em instituições de ensino superior baseado em previsão de receita. Ingepro: Inovação, Gestão e Produção. v. 3, p. 74-83, 2011.

YIN, R. K. Estudo de Caso: planejamento e método. $3^{\text {a }}$ ed. Porto Alegre: Bookman, 2005. 